\title{
Antimicrobial peptides grafted onto a plasma polymer interlayer platform: performance upon extended bacterial challenge
}

\author{
Stefani S. Griesser, Marek Jasieniak, Krasimir Vasilev, Hans J. Griesser *
}

Future Industries Institute, University of South Australia, Mawson Lakes, SA 5095, Australia

* Author for correspondence; email hans.griesser@unisa.edu.au

\begin{abstract}
To combat infections on biomedical devices, antimicrobial coatings have attracted considerable attention, including coatings comprising naturally occurring antimicrobial peptides (AMPs). In this study the aim was to explore performance upon extended challenge by bacteria growing in media above samples. The AMPs LL37, Magainin 2, and Parasin 1 were covalently grafted onto a plasma polymer platform, which enables application of this multilayer coating strategy to a wide range of biomaterials. Detailed surface analyses were performed to verify the intended outcomes of the coating sequence. Samples were challenged by incubation in bacterial growth media for 5 and $20 \mathrm{hrs}$. Compared with the control plasma polymer surface, all three grafted AMP coatings showed considerable reductions in bacterial colonization even at the high bacterial challenge of initial seeding at $1 \times 10^{7} \mathrm{CFU}$, but there were increasing numbers of dead bacteria attached to the surface. All three grafted AMP coatings were found to be non-toxic to primary fibroblasts. These coatings thus could be useful to produce antibacterial surface coatings for biomaterials, though possible consequences arising from the presence of dead bacteria need to be studied further, and compared to non-fouling coatings that avoid attached dead bacteria.
\end{abstract}

Keywords: antibacterial coating, antimicrobial peptide, plasma polymer, LL 37, Magainin, Parasin, bacterial attachment 


\section{Introduction}

The occurrence of infections on biomedical devices such as catheters, hip and knee implants, contact lenses, and many others, is a major challenge in healthcare leading to patient morbidity and mortality, and enormous added costs.[1-5] Many of these infection arise from the ability of bacterial and fungal pathogens to attach to surfaces of devices, proliferate, and form biofilms.[4,5] Once formed, such infectious biofilms are difficult to eradicate.[4,5] Accordingly, there has been much interest in research aimed at developing surfaces and coatings that can prevent device-associated infections, by stopping either microbial attachment or the ability of attached microbes to convert to the biofilm-forming phenotype.[6-9]

One class of molecules that has attracted considerable interest for the development of antimicrobial coatings is that of antimicrobial peptides (AMPs).[10-15] AMPs are part of the innate immune system and are involved in the first line of defence against bacterial invasion for all multicellular organisms.[10,11] AMPs have been isolated from a wide variety of animals, plants, bacteria, fungi and virus.[11] They function as both antimicrobial agents and modulators of the immune system.[14,16] Although they are highly diverse, they have three characteristics that are shared by almost all known AMPs: a relatively small size (10-40 amino acids), a highly cationic character, and an amphipathic nature.[17] AMPs offer many significant potential advantages in that they have broad-spectrum activity across a broad range of Gram-positive and Gram-negative bacteria, including drug-resistant strains, and are also active against fungi.[11,18] Many AMPs target bacterial membrane function and stability, rather than specific protein binding sites.[18] This makes them highly advantageous because they can kill microbes in growing and non-growing states and in dormancy, and do not induce resistance.[13]

A natural extension to the extensive research in AMPs is their application to solid surfaces of materials and medical devices via various chemistries to deter bacterial surface colonisation and biofilm formation.[17,19-21] To retain AMPs on surfaces of biomedical devices in biological environments, they must be bound covalently ("grafted") to the biomaterial surface. There are many reports on grafting of AMPs onto various materials by various interfacial linking chemistries, as discussed in recent reviews.[22-24] In this study, we have utilized the approach of using a plasma polymer interlayer bearing surface aldehyde groups that can react with amine groups of AMPs to form an interfacial covalent bond.[25] The attraction of using a plasma polymer interlayer is that identical plasma polymers can facilely be deposited onto a wide range of materials and devices, and hence our coating strategy is generically applicable to a wide range of potential products.[7,25-27] Other surface modification 
techniques are typically limited to specific substrate materials. For example, Layer by Layer deposition requires a charged surface, whilst Self Assembled Monolayers require metallic surfaces in the case of thiols or a silica surface in the case of silanes. [28] Notably, plasma polymers are deposited from the vapour phase of a carefully chosen precursor and thus do not involve the use of solvents. As a consequence, there are no requirements for waste solvent treatment or pollution to the environment. Lastly, the (electrical) energy required for plasma polymerisation can be potentially generated from purely sustainable sources such as solar or wind.

Previous studies with AMPs grafted onto surfaces using other chemistries have shown high effectiveness. $[17,19,20]$ However, typically relatively short inoculation times and moderate bacterial challenges (numbers in solution) were employed. Accordingly, in this study the main focus was, after showing that an aldehyde plasma polymer is suitable for grafting AMPs in an active conformation, on studying effects arising after extended periods of challenging samples with high loads of bacteria. We found that whilst effective initially at resisting bacterial colonization, eventually the coatings became colonized by increasing numbers of dead and live Bacteria. On one coating, once dead bacteria had accumulated this then allowed live bacteria to attach on top of the dead bacterial layer.

\section{Materials and Methods}

\section{AMPs}

For this work, three representative AMPs were selected: LL37(134-170), Magainin 2, and Parasin 1. The amino acid compositions are: LL37 (MW 4493.37 Da): H-Leu-Leu-Gly-AspPhe-Phe-Arg-Lys-Ser-Lys-Glu-Lys-Ile-Gly-Lys-Glu-Phe-Lys-Arg-Ile-Val-Gln-Arg-Ile-LysAsp-Phe-Leu-Arg-Asn-Leu-Val-Pro-Arg-Thr-Glu-Ser-OH; Magainin 2 (MW 2466.95 Da): HGly-Ile-gly-Lys-Phe-Leu-His-Ser-Ala-Lys-Lys-Phe-Gly-Lys-Ala-Phe-Val-Gly-Glu-Ile-MetAsn-Ser-OH; and Parasin 1 (MW 2000.3 Da): H-Lys-Gly-Arg-Gly-Lys-Gln-Gly-Gly-LysVal-Arg-Ala-Lys-Ala-Lys-Thr-Arg-Ser-Ser-OH. They were purchased from both the American Peptide Company, USA, and GL Biochem, Shanghai, China, the latter with >97\% purity.

\section{Grafting methodology}

The reaction scheme for covalent grafting onto the aldehyde plasma polymer (ALDpp) surface via reductive amination is shown schematically in Scheme 1. 


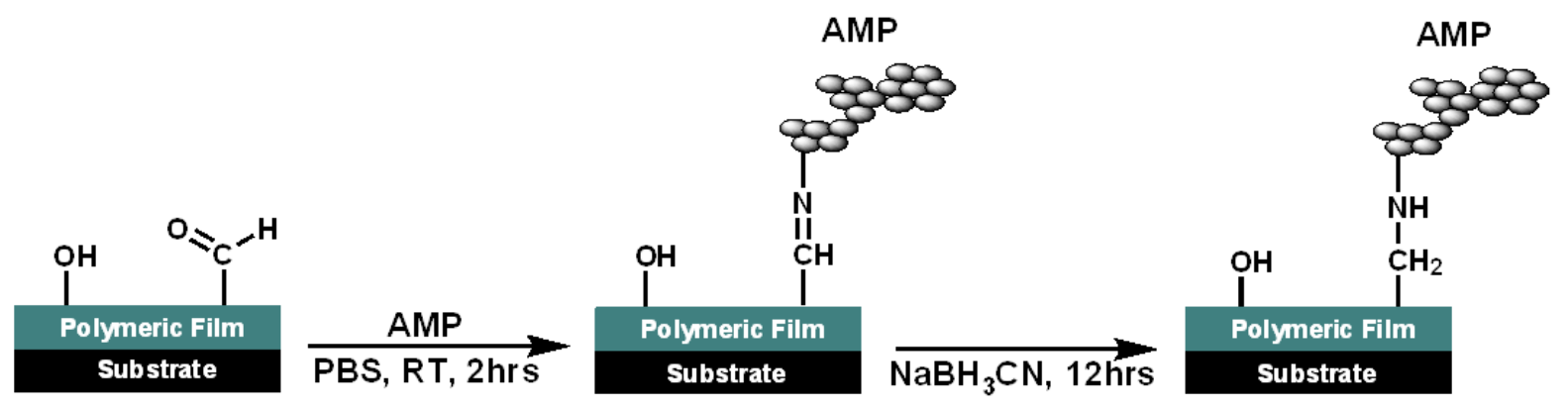

Scheme 1: Immobilisation of AMPs via reductive amination onto ALDpp.

The ALDpp interlayer was deposited in a plasma system described previously [29] and using plasma conditions optimized in a previous study [30] to $\sim 21 \mathrm{~nm}$ thickness, as measured by ellipsometry on $\mathrm{Si}$ wafer substrates, onto several substrates to suit intended tests and demonstrate application to different material surfaces: silicon wafers (MMRC, Malvern, Australia), Thermanox coverslips (GL083, ProSciTech, Brisbane, Australia), ibidi well plates (81201 and 81821, DKSH, Hallam, Australia), and polystyrene slides (ProSciTech, Brisbane, Australia). FlexiPERM 12 reusable masks (Sarstedt, Mawson Lakes, Australia) were used to define areas for coatings. ALDpp coated samples were placed in sterile solutions of $0.1 \mathrm{mg} / \mathrm{ml}$ AMPs in PBS for $2 \mathrm{hrs}$ at $21^{\circ} \mathrm{C}$, followed by addition of an equal volume of sodium cyanoborohydride, $1 \mathrm{mg} / \mathrm{ml}$, and letting reduction proceed at $4{ }^{\circ} \mathrm{C}$ for 12 hours. Samples were then soaked and rinsed six times over 2 hrs with sterile PBS. The final rinse was collected and tested with bacteria to check that no peptide detached into solution and therefore the results were indeed from covalently attached peptides only.

\section{Surface Analysis}

Samples were analyzed using X-ray photoelectron spectroscopy (XPS) and Time-of-Flight Secondary Ion Mass Spectrometry (ToF-SIMS). XPS was performed with a Kratos AXIS Ultra DLD spectrometer, using monochromatic $\mathrm{AlK}_{\alpha}$ radiation $(h v=1486.7 \mathrm{eV})$ and a magnetically confined charge compensation system. Spectra were recorded using an acceleration voltage of $15 \mathrm{keV}$ at a power of $225 \mathrm{~W}$. Survey spectra were collected with a pass energy of $160 \mathrm{eV}$ and an analysis area of $300 \times 700 \mu \mathrm{m}$. High-resolution spectra were obtained using a $20 \mathrm{eV}$ pass energy and an analysis area of $\sim 300 \times 700 \mu \mathrm{m}$. Data analysis was performed with CasaXPS software (Casa Software Ltd). All binding energies were referenced to the neutral component of the $\mathrm{C} 1 \mathrm{~s}$ peak at $285.0 \mathrm{eV}$. Core level envelopes were curve fitted with the minimum number of mixed Gaussian-Lorentzian component profiles. The Gaussian-Lorentzian mixing ratio 
(typically 30\% Lorentzian and 70\% Gaussian functions); the full width at half maximum, and the positions and intensities of peaks were left unconstrained to result in a best fit.

ToF-SIMS measurements were performed with a PHI TRIFT V nanoTOF instrument (PHI Electronics Ltd, USA), with a $30 \mathrm{keV}$, pulsed primary ${ }^{197} \mathrm{Au}^{+}$ion beam and dual beam charge neutralisation using a combination of low-energy argon ions (up to $10 \mathrm{eV}$ ) and electrons (up to $25 \mathrm{eV}$ ). Positive mass axis calibration was done with $\mathrm{CH}_{3}{ }^{+}, \mathrm{C}_{2} \mathrm{H}_{5}{ }^{+}$and $\mathrm{C}_{3} \mathrm{H}_{7}{ }^{+}$. Spectra were acquired in the bunched mode for $60 \mathrm{~s}$ from an area of $100 \mu \mathrm{m} \times 100 \mu \mathrm{m}$. The corresponding total primary ion dose was less than $1 \times 10^{12}$ ions $\mathrm{cm}^{-2}$, and thus met the conditions of the static SIMS regime.[31] A mass resolution $\mathrm{m} / \Delta \mathrm{m}$ of $>7000$ at nominal $\mathrm{m} / \mathrm{z}=$ $27 \mathrm{amu}\left(\mathrm{C}_{2} \mathrm{H}_{3}{ }^{+}\right)$was typically achieved. Some samples were characterised by multiple positive ion mass spectra, collected from sample areas that did not overlap. All peaks not obscured by overlaps in the amu range 2 to 175 were used in Principal Component Analysis (PCA) calculations. Peak intensities were normalized to the total intensity of all peaks. Multiple mass spectra were processed by PCA,[32] using PLS_Toolbox version 3.0 (Eigenvector Research, Inc, Manson, WA) along with MATLAB software v. 6.5 (MathWorks Inc, Natick, MA, USA).

\section{Bacterial testing}

Bacteria (S. epidermidis ATCC 35984, S. aureus MRSA ATCC 43300, and E. coli ATCC 35922) were plated from frozen stock and incubated overnight at $37^{\circ} \mathrm{C}$. Two colonies were picked from plates and grown in $10 \mathrm{ml}$ TSB (Oxoid) overnight at $37^{\circ} \mathrm{C}$, followed by dilution $1 / 100$ and growth to $\log$ phase, then diluted to $1 \times 10^{6}$ bacteria/ml using calibrated spectroscopy measurements. Samples were immersed in $100 \mu \mathrm{l}$ or $300 \mu \mathrm{l}$ of bacterial solutions and left to grow for 5 or $24 \mathrm{hrs}$ at $37^{\circ} \mathrm{C}$, followed by rinsing and analyses using visualization by the LIVE/DEAD BacLight Bacterial Viability assay (Invitrogen), viable bacteria count plating, surface stamping onto agar plates, and safranin staining of biofilm and spectroscopy readings.

BacLight contains two nucleic acid stains: a green fluorescent stain, SYTO 9, which is membrane permeable, and a red fluorescent stain, propidium iodide, which is membrane impermeant and should only stain cells that have compromised membranes. In principle, live bacteria are stained green and dead bacteria are stained red. It is important, however, that the BacLight kit be tested in each system before use to ensure accurate scoring of live and dead cells. This was done by growing bacteria on supporting reference surfaces, and negative controls (dead bacteria) were created by treating bacteria in wells with Virkon for $2 \mathrm{~min}$. The controls showed good reproducibility. In contrast, biofilm staining by safranin was not reliable because of the combination of dead and live bacteria present. 
Polystyrene slides were plasma treated and then a FlexiPERM 12-well removable mask was placed on the slide; AMPs were added to the wells for grafting overnight. After rinsing, bacteria were added for incubation for various periods, followed by rinsing to remove loosely attached bacteria. The wells were treated with the LIVE/DEAD BacLight stain and the mask carefully removed before microscopy examination.

\section{Fibroblasts testing}

Two fibroblast cell lines were used: HFF-1 (human, ATCC SCRC-1041) and 3T3 (NIH-3T3 mouse fibroblast, ATCC CRL-1658), as well as freshly harvested primary fibroblasts from human explant skin, using a reported protocol.[33] All cell cultures were maintained according to ATCC instructions; primary cells were maintained according to.[33] Thermanox coverslip samples were placed in sterile 24-well culture plates (Nunc, Invitrogen) and prewarmed in a cell culture oven. Cells were made up to 50,000 cells per $\mathrm{ml}$ in medium/serum and added at 1 $\mathrm{ml}$ to each well; primary cells were made up to 10,000 cells per ml. Well plates were placed into a culture oven and left for 48 hours. The coverslips were rinsed to remove non-adherent cells and placed on a glass slide and coverslip for immediate microscopic analysis.

\section{Results}

The three AMPs possess amine groups and thus should be amenable to convenient grafting from aqueous solutions onto surface aldehyde or surface epoxy groups, as reported previously for other proteins.[30,34] In this study, to effect grafting onto materials surfaces that per se do not contain aldehyde groups, a plasma polymer interlayer deposited from propanal (aka propionaldehyde) was utilized. Its surface has previously been shown to contain reactive aldehyde groups, [30,34] as well as hydroxyl groups that help provide a hydrophilic nature to the surface, which helps avoid denaturation of grafted proteins. However, reactions at surfaces may differ from reactions in solution and thus, as discussed by Castner and Ratner,[35] coatings need to be appropriately characterized prior to biological tests in order to ensure that biological responses can be interpreted reliably and possible incorrect inferences arising from unrecognized artefacts and contaminants are avoided. To verify that grafting had indeed occurred, XPS and ToF-SIMS analyses were performed.

XPS analysis of samples after immersion in solutions of AMPs showed substantial changes, relative to the ALDpp interlayer, in accord with expectations based on an immobilised protein layer (Table 1). The data show high surface coverage, particularly for LL37. LL37 possesses multiple amine groups, so would naturally have greater capacity for attachment than 
peptides with a smaller number of amine groups. Angle-dependent XPS showed an increase by $\sim 33 \%$ in the $\mathrm{N}$ signal when the take-off angle was changed from $0^{\circ}$ to $75^{\circ}$ (relative to the surface normal). This indicates, as expected, that the peptides are on top of the ALDpp layer, as opposed to possible in-diffusion of the peptides into the ALDpp.

Table 1: Compositions determined by XPS of plasma polymers (ALDpp) on a Thermanox (Th) substrate, and after grafting with antimicrobial peptides

\begin{tabular}{|l|c|c|c|}
\hline \multirow{2}{*}{ Sample } & \multicolumn{3}{|c|}{ Concentration, at\% } \\
\cline { 2 - 4 } & $\mathrm{O}$ & $\mathrm{N}$ & $\mathrm{C}$ \\
\hline Th-ALDpp & 10.6 & 0 & 89.4 \\
\hline Th-ALDpp-LL37 & 12.5 & 5.5 & 82.0 \\
\hline Th-ALDpp-Mg2 & 11.7 & 3.4 & 84.9 \\
\hline Th-ALDpp-Pa1 & 11.3 & 1.5 & 87.1 \\
\hline
\end{tabular}

The component fitting (Table 2) also is in excellent agreement with expectations based on a surface-attached protein layer. In particular, the presence of a component assignable to amide $\mathrm{C}$ confirms that the elemental changes are due to an attached peptide layer, as opposed to possible surface contaminants such as adventitious hydrocarbons or fatty acids or amides. Representative spectra are shown in Figure 1.

Table 2: Component fitting for the XPS C 1s signals recorded with ALDpp and after grafting with antimicrobial peptides

\begin{tabular}{l|c|c|c|c|c}
\hline \multicolumn{1}{c|}{ Sample } & \multicolumn{5}{|c}{ Fitted components in C 1s, [\% of total C] } \\
& C-C/H & C-N & C-O & C=O & N-C=O \\
\hline Th-ALDpp & 87.2 & - & 8.7 & 4.08 & - \\
-ALDpp-LL37 & 67.0 & 11.9 & 11.5 & - & 9.6 \\
-ALDpp-Mg2 & 76.8 & 9.5 & 8.0 & - & 6.4 \\
-ALDpp-Pa1 & 81.5 & 7.8 & 7.0 & - & 3.8 \\
\hline
\end{tabular}



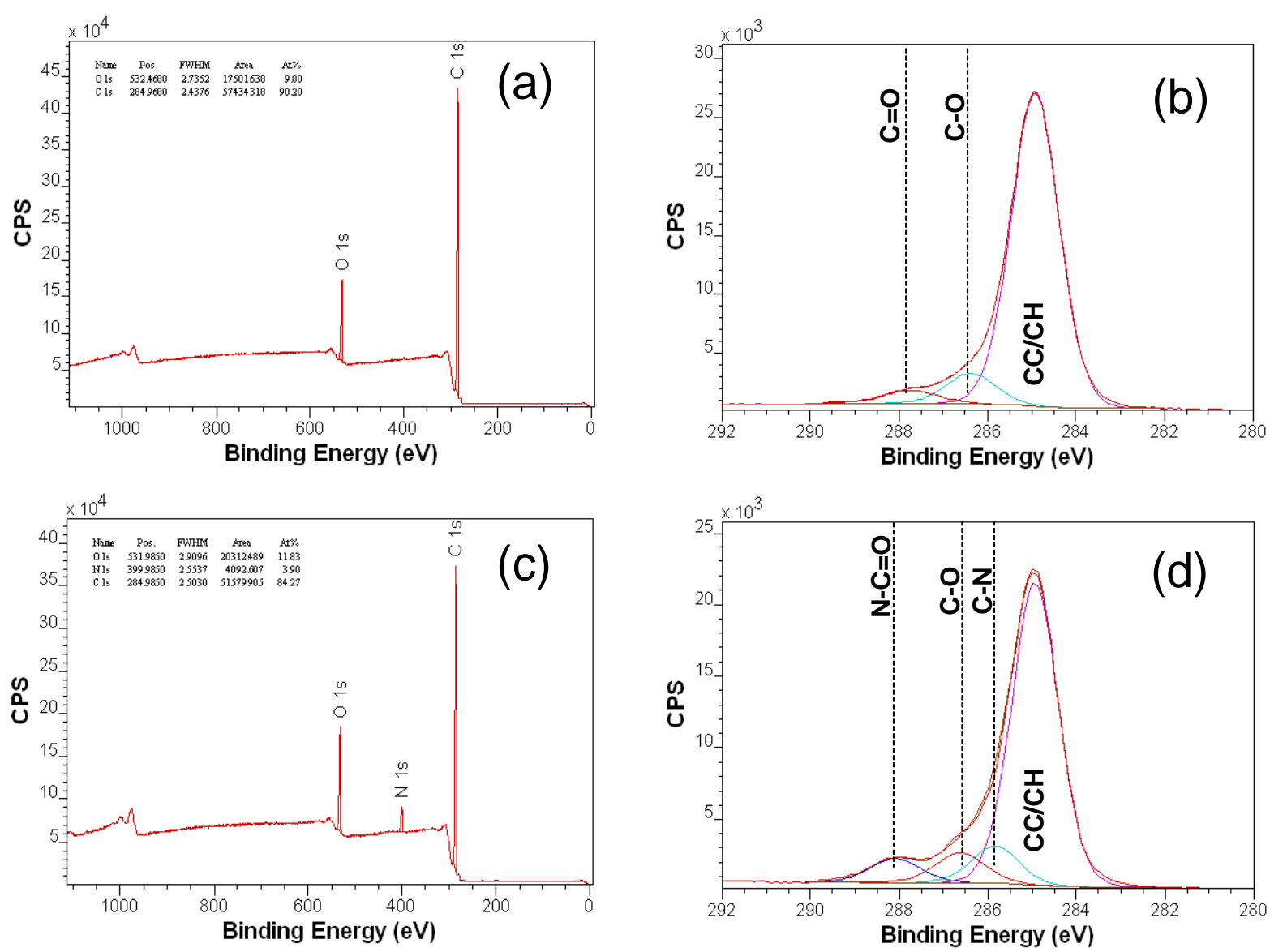

Figure 1: XPS spectra of ALDpp and ALDpp-Mg2 surfaces: (a) ALDpp, survey; (b) ALDpp, C 1s; (c) ALDpp-Mg2, survey; (d) ALDpp-Mg2, C 1s.

ToF-SIMS, a technique capable of providing information on molecular structural elements, also gave spectra (Figures 2 and 3) that verified the presence of the AMPs, via characteristic peaks that could be assigned as originating from specific amino acids, as shown in Figure 2b, on the basis of published immonium ion signals.[36] No such signals appeared in spectra recorded with ALDpp samples. No contamination, particularly by silicones, was detected on any of the samples. Recording spectra on duplicate samples and on several separate areas of a sample also showed excellent reproducibility and uniformity of the coatings. Moreover, samples were washed and soaked extensively to probe whether the AMPs were indeed covalently attached; this did not lead to any measurable changes in spectra. It is noteworthy in Figure 3 that in addition to the commonly observed $\mathrm{C}_{2} \mathrm{H}_{5} \mathrm{~N}^{+}$ion the highresolution spectra after LL37 and Pal grafting also showed a signal attributable to the $\mathrm{CH}_{3} \mathrm{~N}_{2}{ }^{+}$ ion, which arises from arginine residues. 

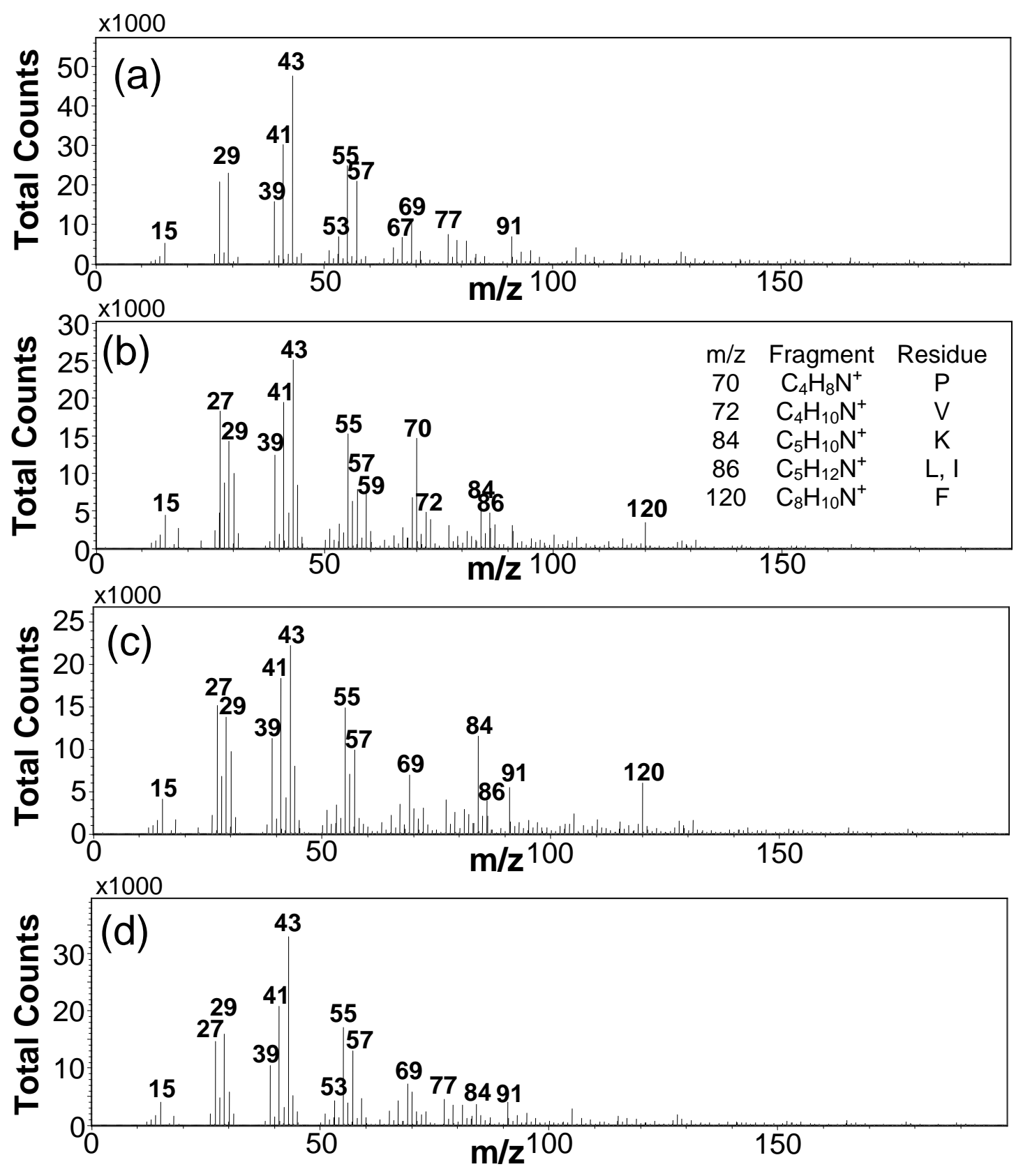

Figure 2: Positive mass spectra of ALDpp and its modifications with antimicrobial peptides:

(a) Thermanox-ALDpp, (b) Th-ALDpp-LL37, (c) Th-ALDpp-Mg2, (d) Th-ALDpp-Pa1. 

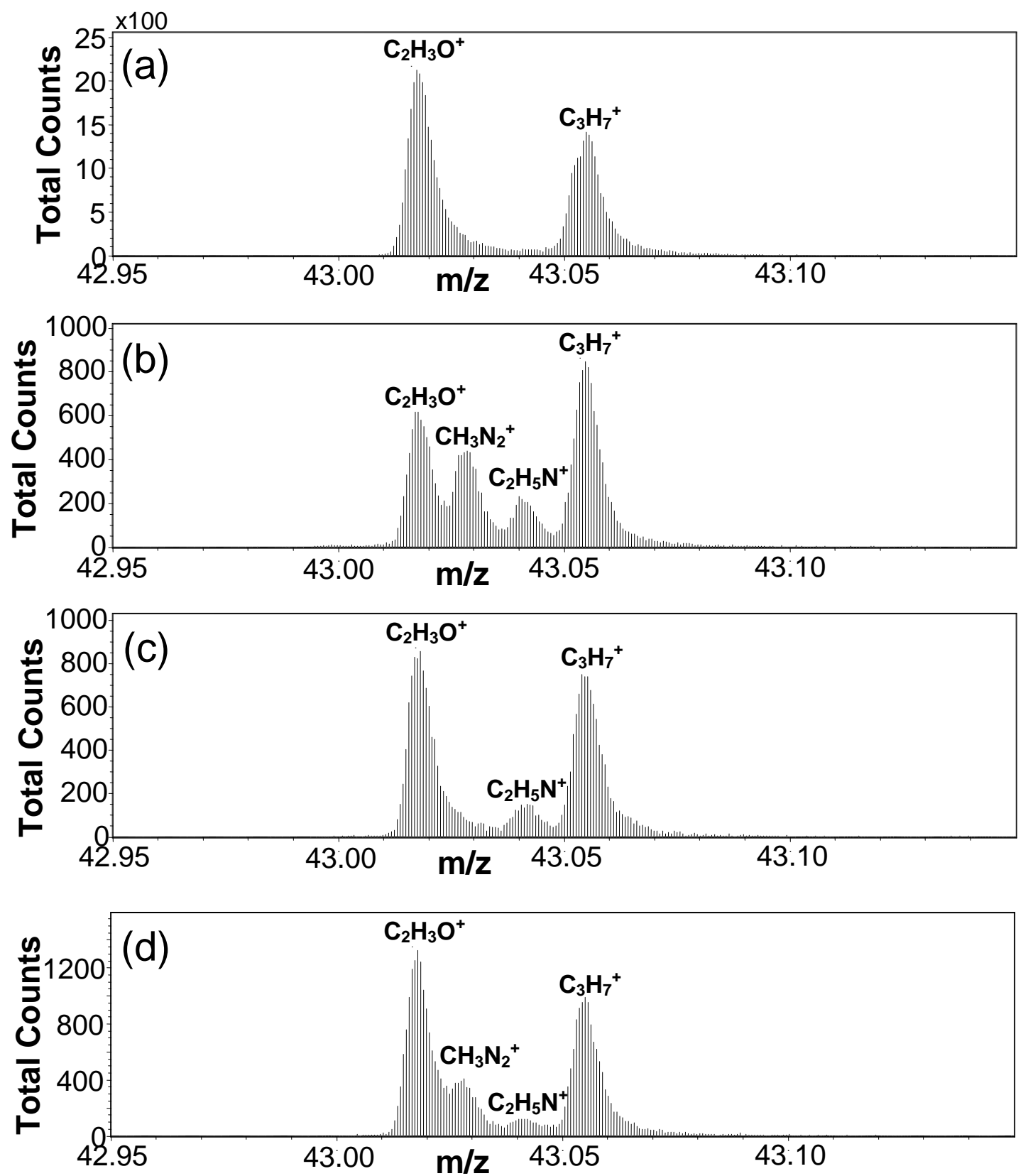

Figure 3: Positive ion mass spectra in the range of m/z 42.95-43.15 for ALDpp and after grafting with antimicrobial peptides: (a) Thermanox-ALDpp, (b) Th-ALDpp-LL37, (c) ThALDpp-Mg2, (d) th-ALDpp-Pa1.

Spectra were further processed by PCA. The scores plot on the first two principal components, which together contained $97 \%$ of the information, is shown in Figure S1 (Supplementary). The tight clustering of data recorded on separate sample areas again shows high uniformity of the surfaces. In agreement with the XPS data showing the lowest $\% \mathrm{~N}$ for parasin, the PCA analysis shows the Pal coating to be less distant from the ALDpp than the other two AMP graft coatings. Loadings plots, two examples of which are reproduced in Figure 
S2 (Supplementary), reveal the individual peaks that contribute most strongly to the differences in surface composition. Not surprisingly, the peaks that load negatively on PC1 (i.e., increase in relative intensity upon grafting of AMPs onto ALDpp) can be assigned to molecular ions that contain N. The loadings plot on PC1 in Figure S2a illustrates that along the PC1 axis the main differences arise in signals assignable to amino acids (loading negatively) and signals assignable to the underlying ALDpp, which load positively and hence are of reduced relative intensity after grafting, as expected. Interestingly, peaks assignable to the amino acid arginine are of reduced relative intensity. Its guanidine side chain should, based on chemical principles, be highly reactive with aldehyde surface groups, more so than the amino side group of lysine. The data suggest that interfacial immobilisation via reaction between arginines and surface aldehydes is an important aspect in the covalent grafting of these AMPs.

In summary, the surface analysis data clearly show that all three AMPs were successfully grafted onto the ALDpp interlayer, with LL37 grafted to the highest surface coverage and Pa1 to the lowest. Repeating these analyses after extended soaking of samples in PBS followed by rinsing gave identical results, indicating that the surface-bound AMPs were covalently grafted and thus not detachable.

\section{Bacterial Testing}

Representative optical microscopy images of bacterial growth on samples after 5 hrs incubation and BacLight staining are shown in Figure 4. On the ALDpp, bacteria attached and grew well, while there was substantially less growth on the AMP surfaces. The images suggest that the grafted Magainin 2 coating performs best, in that it shows few bacteria either dead or alive. On the other two AMP-grafted surfaces there is clear evidence of adhering dead bacteria, as well as a significant number of live bacteria on the LL37 coating. One possible interpretation is that on grafted Magainin 2, surface-contacting bacteria are killed rapidly, before they can establish a sufficiently strong adhesive bond to the surface, whereas on the other two surfaces, some bacteria manage to attach with sufficient strength before they are killed, and thus their dead remnants then do not detach. This seems to be the case less for LL37 than for Pa 1.

For parallel samples, not stained by BacLight, bacteria were removed, serially diluted, and plated on Agar. This gave colony counts of $>3000$ live colonies on the control ALDpp surface, $\sim 150$ colonies on LL37 grafted samples, $\sim 70$ colonies on Magainin 2 grafted samples, and $\sim 300$ colonies on Parasin 1 grafted samples. The dead and dying bacteria, which are particularly prominent on the Parasin 1 grafted coating, however, could not be quantified. 

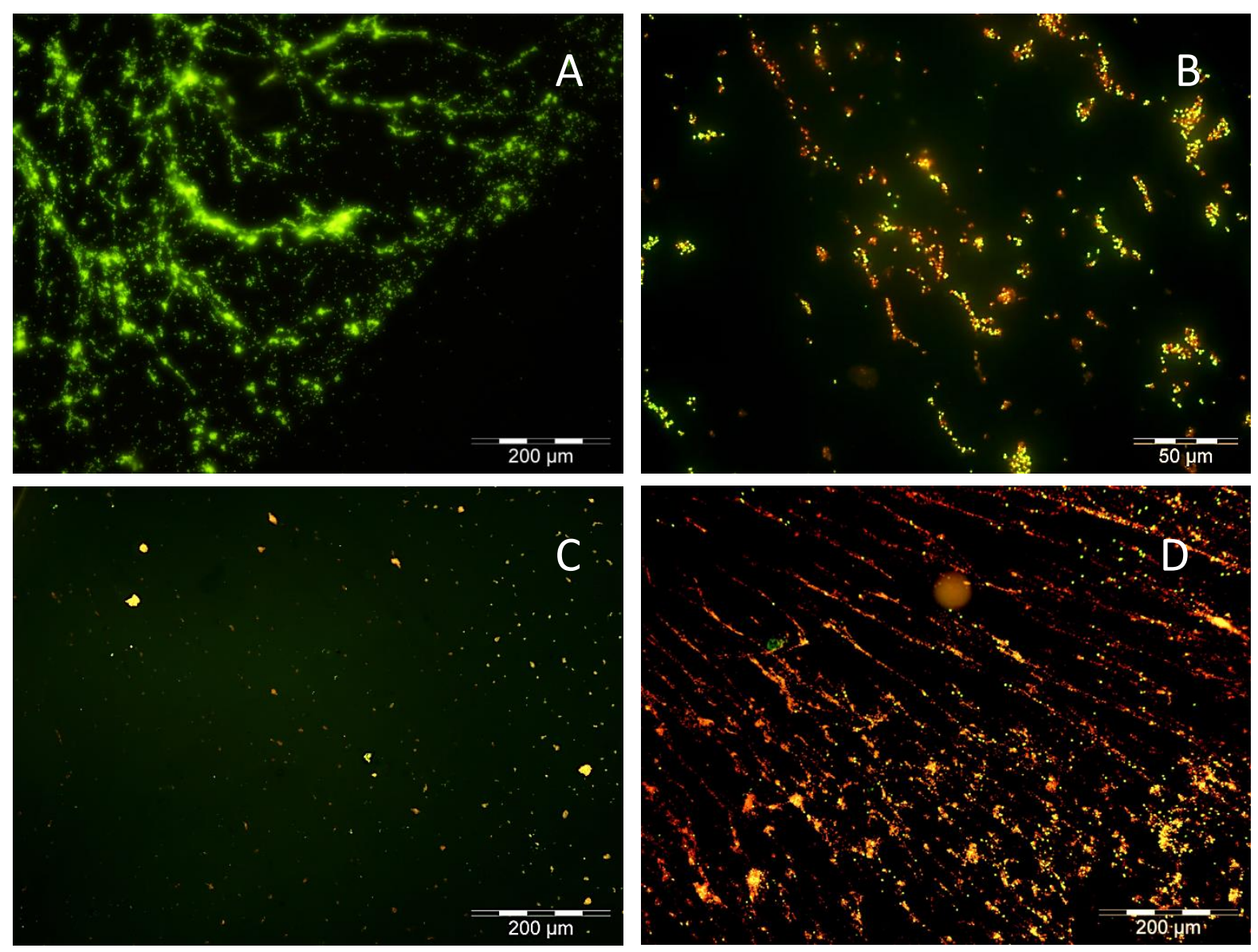

Figure 4: Stained microscopy images of S. epidermidis colonization after 5 hrs incubation, seeded at $1 \times 10^{7} \mathrm{CFU}$, on (A) control aldehyde plasma polymer (ALDpp), on (B) grafted LL37, (C) Magainin 2, and (D) Parasin 1.

Thus, as in previous studies, the grafted AMPs cause a marked reduction in bacterial attachment relative to the reference polymer surface (in this case, ALDpp, which is itself not particularly adhesive for bacteria). However, whilst earlier work often has recorded only the short-term benefits, the observation of attached dead bacteria raises the question as to what the longer-duration consequences might be.

Accordingly, bacterial attachment and growth was studied over longer time frames, keeping samples in the original bacterial growth media solutions, which means that bacterial numbers were increasing steadily and thereby continuously upping the challenges on the coatings' ability to resist bacterial colonization. Representative images recorded with stained samples after $20 \mathrm{hrs}$ of exposure to S. epidermidis solution are shown in Figure 5. 

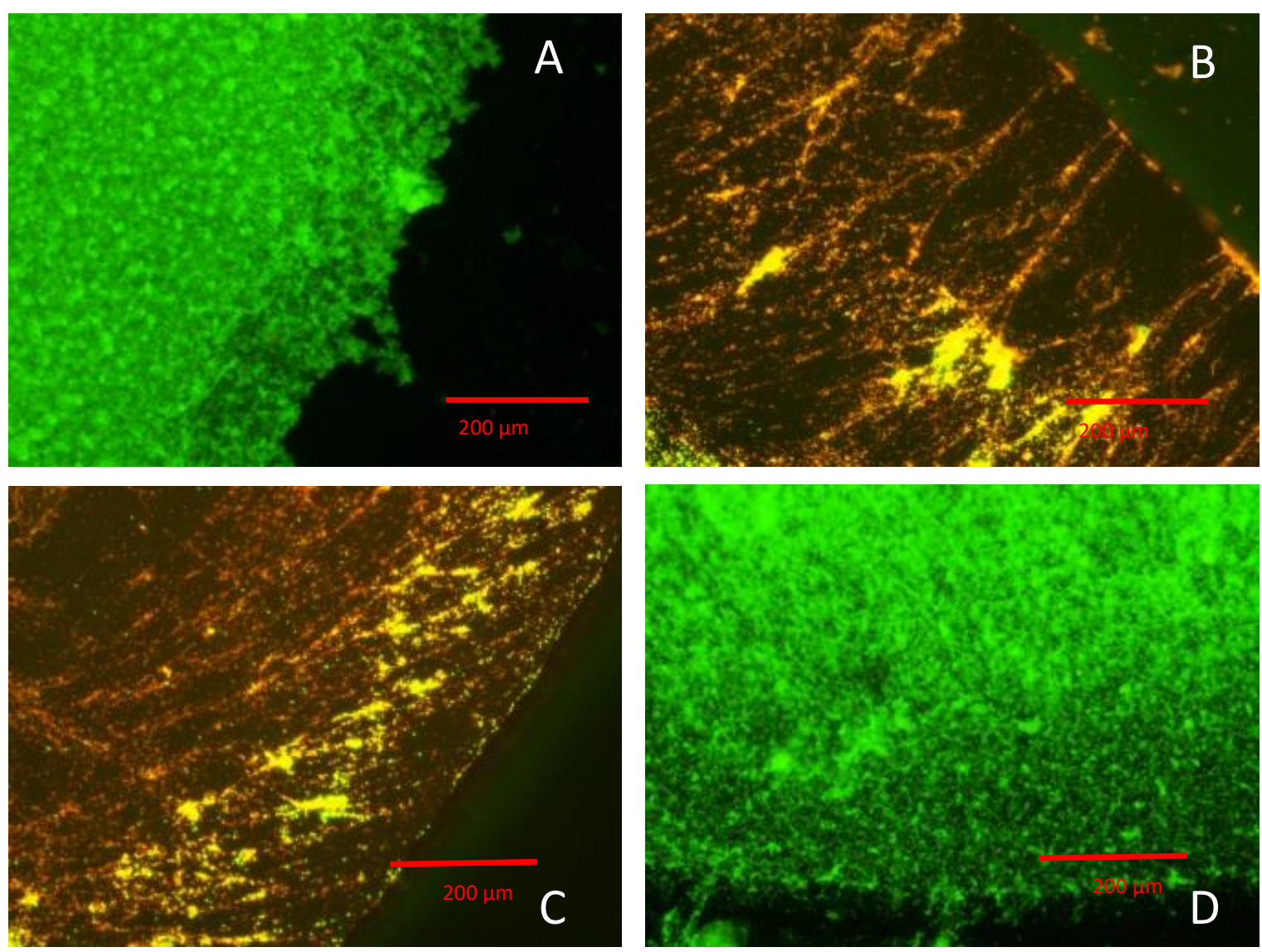

Figure 5: Stained microscopy images of S. epidermidis colonization after 20 hrs incubation, seeded at $1 \times 10^{7} \mathrm{CFU}$, on (A) the control ALDpp surface, (B) Magainin 2 graft coating, (C) Parasin 1 graft coating, and (D) on LL37 graft coating. The edges in the images are due to masks having been placed on samples.

The control ALDpp surface was completely overgrown after 20 hrs (Figure 5A) by apparently live bacteria; there was no evidence of dead (red-stained) bacteria. This is consistent with expectations; this fast-growing strain of S. epidermidis can colonize unprotected surfaces rapidly and proceed to biofilm formation.

The Magainin 2 coating showed larger numbers of bacteria after 20 hrs compared with 5 hrs. Many of the attached bacteria appear to be dead, but there is evidence of colony formation (the yellow clumps in Figure 5B) upon bacterial aggregation. Similarly, the Parasin 1 coating shows (Figure 5C) increasing numbers of attached bacteria, the majority of which seem to be dead according to the staining, but there are live bacteria visible and again the formation of clumps of bacteria. In contrast, the LL37 coating was overgrown by live bacteria after $20 \mathrm{hrs}$ (Figure 5D). As Figure 4B shows a significant number of attached live bacteria after $4 \mathrm{hrs}$ on the LL37 surface, it is not surprising that these attached live bacteria proceed to denser 
coverage. It appears from these data that grafted LL37 is relatively inefficient at killing attaching bacteria.

Whilst clear results were obtained with S. epidermidis, bacterial testing with S. aureus and $E$. coli was more difficult because these bacteria were far less inclined to colonize surfaces, even the ALDpp, very little colonization of the AMP surfaces over the first $5 \mathrm{hrs}$ (data not shown). After $24 \mathrm{hrs}$, however, some colonization was evident on all samples, as for $S$. epidermidis. Lower amounts of bacteria resulted in less colonization up to $10 \mathrm{hrs}$.

These coatings were also tested in the presence of serum to determine whether serum proteins might affect or block the antibacterial activity, for example by adsorbing in a layer thick enough to "bury" the AMPs underneath them. For all coatings, however, the activity was not affected within the first 5 hours; after 6 hours, there were indications again that the surfaces were increasingly becoming colonised. It is difficult to separate any effect due to proteins from the increasing colonisation that also occurs in the absence of proteins, as shown above. All that can be concluded is that serum proteins do not immediately block the activity of the grafted AMPs and thus the coatings would be suitable for blood-contacting applications.

Samples were also soaked for 12 days and tested for activity. No reduction of activity was found. This is consistent with the known stability of interfacial amine bonds. It also verifies covalent grafting; if simply adsorbed on the surface (i.e., without formation of a covalent bond), these peptides, being soluble in PBS, should desorb from the surface.

\section{Fibroblast attachment}

Many studies have reported that AMPs can be cytotoxic. With AMPs such as melittin, which is isolated from bee venom, it is an obvious concern. Studies with Magainin and Parasin have found them to be cytotoxic.[37-40] Magainin 2 was developed to limit the toxicity relative to its parent compound.[39] It is, however, not clear whether toxicity is still a relevant concern when peptides are covalently tethered, because most toxicity issues are manifested in renal and hepatic sites through the processes of breaking down the compounds and excreting the products. However, as these AMPs disrupt bacterial membranes, it is essential to study possible adverse effects on mammalian cells even when the peptides are surface-grafted.

Cell attachment was assessed on AMP-grafted surfaces and on two control surfaces (TCPS and ALDpp). Figure 6 shows data collected with primary human fibroblasts; with the fibroblast cell lines the data were closely analogous (not shown). The ALDpp surface gave results identical within experimental uncertainty to the attachment observed on the standard tissue culture surface TCPS. After grafting the AMPs onto the ALDpp layer, there was no difference in cell attachment and growth for LL37 and Magainin 2, whereas for Parasin 1 there 
were fewer cells on the surface and they showed some morphological abnormalities. However, these tests were done with a Parasin 1 sample that was of only $76 \%$ purity and it was impossible to elucidate what the cause of the toxicity might be. Subsequent tests using a Parasin 1 lot of 98.2\% purity (grafted again on ALDpp) showed little to no toxicity and the cells were perhaps somewhat smaller, yet almost as numerous as on the ALDpp control and the other AMP-grafted samples. Accordingly, the AMP-grafted coatings look promising in that there appears to be no substantial cytotoxicity, though with Parasin 1 there should be further work before moving to an animal model, particularly assessing the purity of the peptide sample.

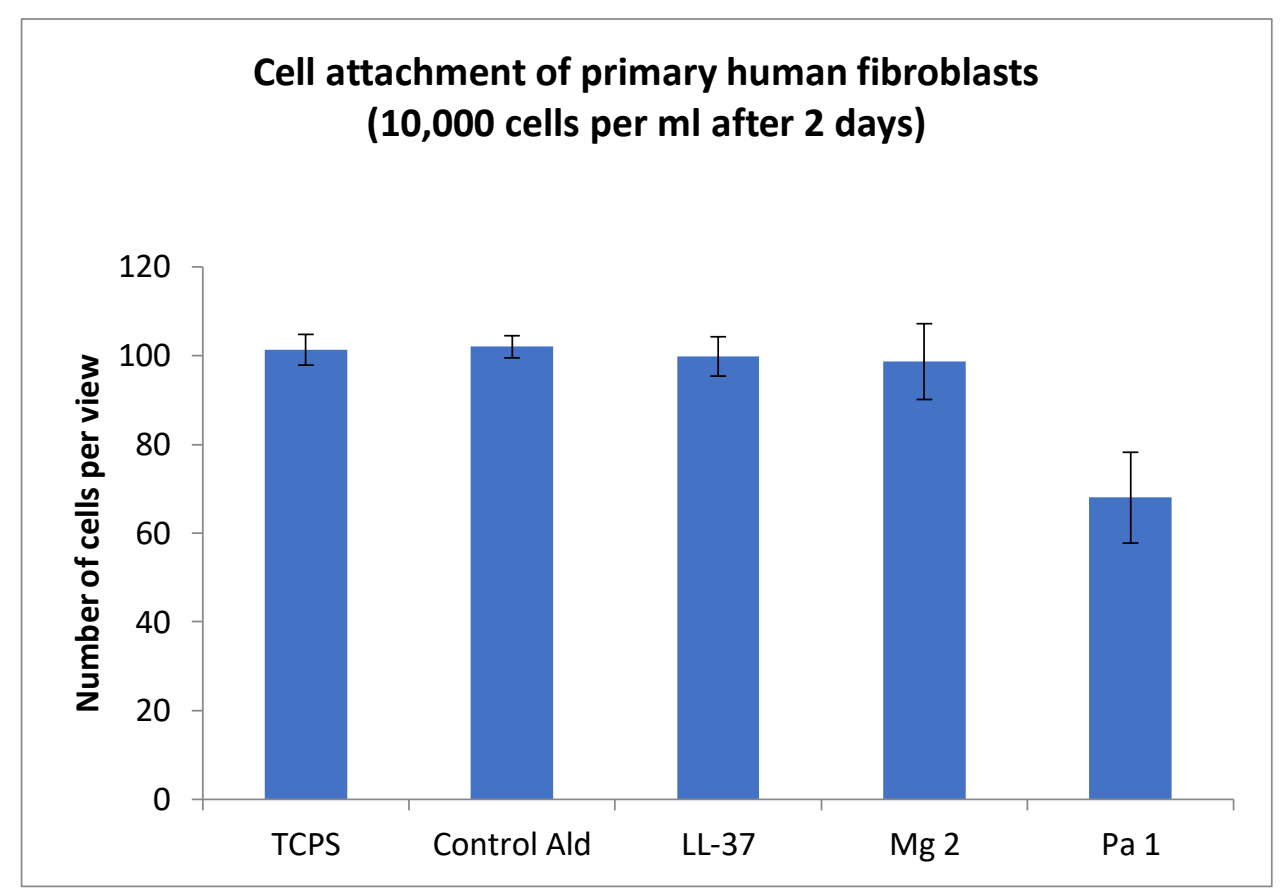

Figure 6: Attachment of primary human fibroblasts on control samples and on AMP-grafted surfaces, counted per field of view at 10x magnification.

\section{Discussion}

AMPs have attracted considerable interest for the design of antibacterial coatings, [13-15,22-24] but some aspects, particularly longer-term performance, are still in need of further study, as is the question of whether some AMPs might be less effective due to conformational changes or accessibility after grafting with specific immobilization chemistries. Their potential use as covalently grafted protective coatings needs to be informed by considerations such as mechanism(s) of action and possible cytotoxicity. AMPs exist in many tissues and various cells in a wide variety of plant and animal species. LL37 (active sequence 134-170) is cleaved extracellularly from hCAP18 by proteinase 3 when hCAP-18 is stimulated,[41] with the name 
LL37 denoting 37 amino acids starting with two leucines. It is a cationic, amphipathic $\alpha$-helical peptide with broad-spectrum antimicrobial activity.[42] It is an effector of the innate immune system and expressed in leukocytes and epithelial cells, and in neutrophils and keratinocytes of inflamed skin. Magainin 2 also is a linear cationic $\alpha$-helical peptides and the mechanism of activity is thought to be similar, through transmembrane pore formation, whilst Parasin 1, from catfish skin mucosa, is a histone $\mathrm{H} 2 \mathrm{~A}$-derived amphipathic $\alpha$-helical peptide upregulated via matrix metalloproteinase 2. It has pore-forming ability; the $\mathrm{N}$-terminal binds to the membrane, the $\alpha$-helical structure inserts either in a barrel-stave or snorkel manner, causing permeabilization. A single lysine residue near the $\mathrm{N}$-terminal in the random coil region is essential to the mechanism of action; one possible explanation is that this anchors the peptide into the membrane, causing destabilization of the membrane and allowing the peptide to become embedded into the bacterial membrane. However, because of its similarity to the histone H2A-derived peptide buforin II, it is also believed to induce intracellular killing by binding to nucleic acids. [43,44]

Such information is essential for selecting candidate AMPs and for rationalizing their performance as grafted surface coatings. The membrane destabilization mechanism of cationic amphipathic $\alpha$-helical peptides could reasonably be expected to be maintained upon grafting to a solid surface; this is borne out by the observed high activity after $5 \mathrm{hrs}$ of incubation. For Parasin 1 grafted onto ALDpp the putative intracellular activity would, of course, not be available upon grafting.[43,44] The observed activity indicates, however, that its ability for membrane permeabilization is retained upon surface grafting.

Another important consideration is to ascertain that the peptides have indeed been applied onto solid polymer surfaces to sufficient coverage, that adventitious other molecules, in particular organosilicones which can be found in proteins due to manufacturing processes or storage containers, are not present, and that the intended formation of covalent interfacial bonds has indeed taken place. Physico-chemical surface analysis methodologies are thus essential to ascertain that coatings are properly characterized prior to biological tests, thereby ensuring that interpretation of biological responses is not affected by artefacts and contaminants.[35]

Extended soaking/washing followed by identical surface analysis experiments are essential for verifying that the coated peptides are indeed covalently grafted and thus are not able to detach during biological tests. Many reports on antimicrobial coatings were not supported with appropriate surface analysis and washing experiments, raising the question whether they were indeed fully covalently immobilised, or whether dissolving antibiotics might 
have affected biological testing.[45] Are some promising results possibly due to unrecognised diffusion of antibiotics intercepting bacteria approaching biomaterials surfaces? Our XPS and ToF-SIMS spectra clearly show grafting of all three peptides with good surface coverage; the precise coverage is difficult to determine due to the assumptions that have to be made when converting XPS atomic percentages to surface coverage, but our data are consistent with grafting densities of $\sim 1 / 3$ to $2 / 3$ of a monolayer of peptides. Repeat surface analyses after extended soaking gave the same data and thus confirmed the covalent nature of the surface binding. This is not surprising; with their solubility in PBS these peptides would not be expected to show high affinity for (non-covalent) physisorption onto the relatively hydrophilic surface of the ALDpp and upon washing with PBS any small adsorbed amounts should readily dissolve off the surface.

Next, it is essential to check that an antimicrobial coating does not exhibit any significant cytotoxicity to mammalian cells. Peptides that destabilize bacterial membranes could also cause adverse effects to human cell membranes. With human-derived peptides this is less of a concern, but others need to be tested and there exists considerable information on this. For the present case, compared with Magainin 1, Magainin 2 has a lower hydrophobicity and was found to be non-haemolytic and non-toxic to human cells.[46] But it is conceivable that conformational changes upon surface grafting might alter the interactions of a grafted AMP with human cell membranes compared with those of a molecule in solution; the graft coating might be more cytotoxic or less cytotoxic. Moreover, this is likely to be dependent also on the grafting chemistry employed. Our results show no measurable toxicity for these three AMPs when grafted onto ALDpp.

Clearly, these grafted AMPs exhibit substantial antibacterial activity, consistent with previous reports on AMP coatings grafted using other immobilization chemistries. Yet, our data recorded after $20 \mathrm{hrs}$ incubation also reveal a decrease in effectiveness upon continuing bacterial challenge. On the Magainin 2 and Parasin 1 graft coatings there is evidence of increasing numbers of attached dead bacteria and of initial formation of colonies. The LL37 graft coating was overgrown.

Many publications mention proteolytic degradation of AMPs,[17,47] but while this may apply to a wound environment for example, it is doubtful whether proteolytic enzymes are at work in the test system used. A more likely explanation seems to be that on the LL37 coating some bacteria are not killed and thus end up initiating colonies. On the other two coatings such colony formation also seems to occur, to a much smaller extent. A putative interpretation is 
that grafted LL37 is relatively less efficient, or less rapid, at killing bacteria that come into contact with its surface, and eventually sufficient numbers survive.

The increasing presence with time of dead bacteria, attached with sufficient strength to resist rinsing, on the surface of the graft coatings poses concerns as to its implications if such coatings were to proceed to practical usage on biomedical devices. First, dead bacteria might eventually cover the grafted AMP layer and bacteria attaching on top of this layer of dead bacteria are not exposed to the action of surface-immobilised AMPs. This might be part of what happens on our LL37 coating. Secondly, the membrane permeabilization of attached bacteria might release endotoxins. This was beyond the scope of the present work.

Whilst the Magainin 2 and the Parasin 1 coatings showed high effectiveness in resisting biofilm formation, the presence of a significant number of dead bacteria raises important questions. It invites comparison with coatings that resist bacterial attachment by physicochemical means such as hydration (non-fouling hydrogel coatings) [48-51], for which there have been no reports of increasing numbers of attached dead bacteria. Perhaps a coating that resists bacterial attachment altogether, as opposed to killing attaching bacteria, might be preferable for clinical applications on biomedical devices used in human medicine.

\section{Conclusions}

AMPs immobilized via reductive amination onto a solid surface bearing aldehyde groups are tethered in a way that allows them to maintain an active conformation. A plasma polymer layer deposited from propanal has been found to be well suited as an adhesive interlayer for the grafting of the three AMPs. Plasma polymerization is a coating technology used to modify surfaces in a number of industries, and will enable transfer of the current grafting approach to a wide range of substrate materials. Detailed surface analyses showed that the intended grafting had indeed taken place and uniform graft coatings had been produced. The coatings did not exhibit significant cytotoxicity to primary human fibroblasts. All three AMPs were found to retain antibacterial activity when covalently grafted, with substantial reductions in bacterial colonization compared to the control plasma polymer surface. These AMPs on ALDpp can thus be used to make effective antibacterial surface coatings for biomaterials by killing most attaching bacteria, but the detection of increasing numbers of attached dead bacteria, and some live bacteria, over time raises questions and invites comparison with non-fouling coatings, which resist the attachment of dead (and live) bacteria and thereby avoid possible detrimental consequences arising from surface-bound dead bacteria. 


\section{Funding}

This work was supported by the CRC for Wound Management Innovation, which is acknowledged for granting a PhD scholarship to SSG. KV thanks the NHMRC for Fellowship APP1122825 and Project grant APP1032738.

\section{Acknowledgments}

We gratefully acknowledge subsidised hands-on access to the surface analytical instruments XPS and ToF-SIMS at the UniSA node of Microscopy Australia, a national network funded under the Australian Government's NCRIS scheme.

\section{Conflicts of Interest}

The authors declare no conflict of interest. The funders had no role in the design of the study; in the collection, analyses, or interpretation of data; in the writing of the manuscript, or in the decision to publish the results.

\section{References}

1. Perez-Koehler, B.; Bayon, Y.; Bellón, J.M. Mesh infection and hernia repair: a review. Surgical Infections 2016, 17, 124-137.

2. Rattanawong, P.; Kewcharoen, J.; Mekraksakit, P.; Mekritthikrai, R.; Prasitlumkum, N.; Vutthikraivit, W.; Putthapiban, P.; Dworkin, J. Device infections in implantable cardioverter defibrillators versus permanent pacemakers: A systematic review and meta-analysis. Journal of Cardiovascular Electrophysiology 2019, 30, 1053-1065.

3. Scotland, K.B.; Lo, J.; Grgic, T.; Lange, D. Ureteral stent-associated infection and sepsis: pathogenesis and prevention: a review. Biofouling 2019, 35, 117-127.

4. Veerachamy, S.; Yarlagadda, T.; Manivasagam, G.; Yarlagadda, P.K. Bacterial adherence and biofilm formation on medical implants: a review. Proceedings of the Institution of Mechanical Engineers, Part H: Journal of Engineering in Medicine 2014, 228, 1083-1099.

5. Vickery, K.; Hu, H.; Jacombs, A.S.; Bradshaw, D.A.; Deva, A.K. A review of bacterial biofilms and their role in device-associated infection. Healthcare infection 2013, 18, 61-66.

6. Vasilev, K.; Cook, J.; Griesser, H.J. Antibacterial surfaces for biomedical devices. Expert Review of Medical Devices 2009, 6, 553-567.

7. Vasilev, K.; Griesser, S.S.; Griesser, H.J. Antibacterial surfaces and coatings produced by plasma techniques. Plasma Processes and Polymers 2011, 8, 1010-1023.

8. Campoccia, D.; Montanaro, L.; Arciola, C.R. A review of the biomaterials technologies for infection-resistant surfaces. Biomaterials 2013, 34, 8533-8554.

9. Chouirfa, H.; Bouloussa, H.; Migonney, V.; Falentin-Daudré, C. Review of titanium surface modification techniques and coatings for antibacterial applications. Acta Biomaterialia 2019, 83, 37-54. 
10. Baltzer, S.A.; Brown, M.H. Antimicrobial peptides-promising alternatives to conventional antibiotics. Journal of Molecular Microbiology and Biotechnology 2011, 20, 228-235.

11. Brogden, K.A. Antimicrobial peptides: pore formers or metabolic inhibitors in bacteria? Nature Reviews Microbiology 2005, 3, 238-250.

12. Yasir, M.; Willcox, M.D.P.; Dutta, D. Action of antimicrobial peptides against bacterial biofilms. Materials 2018, 11, 2468.

13. Magana, M.; Pushpanathan, M.; Santos, A.L.; Leanse, L.; Fernandez, M.; Ioannidis, A.; Giulianotti, M.A.; Apidianakis, Y.; Bradfute, S.; Ferguson, A.L. The value of antimicrobial peptides in the age of resistance. The Lancet Infectious Diseases 2020, 20, e216-e230.

14. Haney, E.F.; Straus, S.K.; Hancock, R.E. Reassessing the host defense peptide landscape. Frontiers in Chemistry 2019, 7, 43.

15. Ting, D.S.J.; Beuerman, R.W.; Dua, H.S.; Lakshminarayanan, R.; Mohammed, I. Strategies in Translating the Therapeutic Potentials of Host Defense Peptides. Frontiers in Immunology 2020, 11, 983.

16. Barns, K.J.; Weisshaar, J.C. Real-time attack of LL-37 on single Bacillus subtilis cells. Biochimica et Biophysica Acta (BBA)-Biomembranes 2013, 1828, 1511-1520.

17. Costa, F.; Carvalho, I.F.; Montelaro, R.C.; Gomes, P.; Martins, M.C.L. Covalent immobilization of antimicrobial peptides (AMPs) onto biomaterial surfaces. Acta biomaterialia 2011, 7, 1431-1440.

18. Wimley, W.C.; Hristova, K. Antimicrobial peptides: successes, challenges and unanswered questions. The Journal of Membrane Biology 2011, 239, 27-34.

19. Yasir, M.; Dutta, D.; Hossain, K.R.; Chen, R.; Ho, K.K.; Kuppusamy, R.; Clarke, R.J.; Kumar, N.; Willcox, M.D. Mechanism of action of surface immobilized antimicrobial peptides against Pseudomonas aeruginosa. Frontiers in Microbiology 2020, 10, 3053.

20. Yasir, M.; Dutta, D.; Kumar, N.; Willcox, M.D. Interaction of the surface bound antimicrobial peptides melimine and Mel4 with Staphylococcus aureus. Biofouling 2020, 1-12, doi:https://doi.org/10.1080/08927014.2020.1843638.

21. Yazici, H.; O’Neill, M.B.; Kacar, T.; Wilson, B.R.; Oren, E.E.; Sarikaya, M.; Tamerler, C. Engineered chimeric peptides as antimicrobial surface coating agents toward infection-free implants. ACS Applied Materials \& Interfaces 2016, 8, 5070-5081.

22. Riool, M.; de Breij, A.; Drijfhout, J.W.; Nibbering, P.H.; Zaat, S.A. Antimicrobial peptides in biomedical device manufacturing. Frontiers in Chemistry 2017, 5, 63.

23. Pinto, I.B.; dos Santos Machado, L.; Meneguetti, B.T.; Nogueira, M.L.; Carvalho, C.M.E.; Roel, A.R.; Franco, O.L. Utilization of antimicrobial peptides, analogues and mimics in creating antimicrobial surfaces and bio-materials. Biochemical Engineering Journal 2019, 150, 107237.

24. Kazemzadeh-Narbat, M.; Cheng, H.; Chabok, R.; Alvarez, M.M.; De La Fuente-Nunez, C.; Phillips, K.S.; Khademhosseini, A. Strategies for antimicrobial peptide coatings on medical devices: a review and regulatory science perspective. Critical Reviews in Biotechnology 2020, $1-27$.

25. Siow, K.S.; Britcher, L.; Kumar, S.; Griesser, H.J. Plasma methods for the generation of chemically reactive surfaces for biomolecule immobilization and cell colonization-a review. Plasma Processes and Polymers 2006, 3, 392-418.

26. Vasilev, K.; Michelmore, A.; Griesser, H.J.; Short, R.D. Substrate influence on the initial growth phase of plasma-deposited polymer films. Chemical Communications 2009, 36003602.

27. Vasilev, K.; Michelmore, A.; Martinek, P.; Chan, J.; Sah, V.; Griesser, H.J.; Short, R.D. Early stages of growth of plasma polymer coatings deposited from nitrogen-and oxygencontaining monomers. Plasma Processes and Polymers 2010, 7, 824-835. 
28. Hernandez-Lopez, J.; Bauer, R.; Chang, W.-S.; Glasser, G.; Grebel-Koehler, D.; Klapper, M.; Kreiter, M.; Leclaire, J.; Majoral, J.-P.; Mittler, S. Functional polymers as nanoscopic building blocks. Materials Science and Engineering: C 2003, 23, 267-274.

29. Griesser, H.J. Small scale reactor for plasma processing of moving substrate web. Vacuum 1989, 39, 485-488.

30. Coad, B.R.; Scholz, T.; Vasilev, K.; Hayball, J.D.; Short, R.D.; Griesser, H.J. Functionality of proteins bound to plasma polymer surfaces. ACS Applied Materials \& Interfaces 2012, 4, 2455-2463.

31. Briggs, D Surface analysis of polymers by XPS and static SIMS, Cambridge University Press, 1998.

32. Jasieniak, M.; Graham, D.; Kingshott, P.; Gamble, L.; Griesser, H.J. Surface Analysis of Biomaterials, in : Handbook of Surface and Interface Analysis, $2^{\text {nd }}$ Edition; J.P. Riviere and S. Myhra (Eds.), CRC Press, p. 529-564, 2009.

33. MacNeil, S.; Shepherd, J.; Smith, L. Production of tissue-engineered skin and oral mucosa for clinical and experimental use. In 3D cell culture, Springer: 2011; pp. 129-153.

34. Coad, B.R.; Vasilev, K.; Diener, K.R.; Hayball, J.D.; Short, R.D.; Griesser, H.J. Immobilized streptavidin gradients as bioconjugation platforms. Langmuir 2012, 28, 2710-2717.

35. Castner, D.G.; Ratner, B.D. Biomedical surface science: Foundations to frontiers. Surface Science 2002, 500, 28-60.

36. Wagner, M.S.; D.G. Castner, D.G Characterization of Adsorbed Protein Films by Time-ofFlight Secondary Ion Mass Spectrometry with Principal Component Analysis. Langmuir, 2001, $17,4649-4660$.

37. Jang, S.A.; Kim, H.; Lee, J.Y.; Shin, J.R.; Kim, D.J.; Cho, J.H.; Kim, S.C. Mechanism of action and specificity of antimicrobial peptides designed based on buforin IIb, Peptides, 2012, 34, 283289.

38. Nascimento, J.M.; Franco, O.L.; Oliveira, M.D.L.; Andrade, C.A.S. Evaluation of magainin I interactions with lipid membranes: an optical and electrochemical study. Chemistry and Physics of Lipids, 2012, 165, 537-544.

39. Tachi, T.; Epand, R.F.; Epand, R.M.; Matsuzaki, K. Position-dependent hydrophobicity of the antimicrobial magainin peptide affects the mode of peptide-lipid interactions and selective toxicity. Biochemistry 2002, 41, 10723-10731.

40. Vila-Farres, X.; de la Maria, C.G.; Lopez-Rojas, R.; Pachon, J.; Giralt, E.; Vila, J. In vitro activity of several antimicrobial peptides against colistin-susceptible and colistin-resistant Acinetobacter baumannii. Clinical Microbiology and Infection, 2012, 18, 383-387.

41. Sørensen, O.E.; Follin, P.; Johnsen, A.H.; Calafat, J.; Tjabringa, G.S.; Hiemstra, P.S.; Borregaard, N. Human cathelicidin, hCAP-18, is processed to the antimicrobial peptide LL-37 by extracellular cleavage with proteinase 3. Blood, The Journal of the American Society of Hematology 2001, 97, 3951-3959.

42. Dürr, U.H.; Sudheendra, U.; Ramamoorthy, A. LL-37, the only human member of the cathelicidin family of antimicrobial peptides. Biochimica et Biophysica Acta (BBA)Biomembranes 2006, 1758, 1408-1425.

43. Koo, Y.S.; Kim, J.M.; Park, I.Y.; Yu, B.J.; Jang, S.A.; Kim, K.-S.; Park, C.B.; Cho, J.H.; Kim, S.C. Structure-activity relations of parasin $\mathrm{I}$, a histone $\mathrm{H} 2 \mathrm{~A}$-derived antimicrobial peptide. Peptides 2008, 29, 1102-1108.

44. Uyterhoeven, E.T.; Butler, C.H.; Ko, D.; Elmore, D.E. Investigating the nucleic acid interactions and antimicrobial mechanism of buforin II. FEBS Letters 2008, 582, 1715-1718.

45. Naderi, J.; Giles, C.; Saboohi, S.; Griesser, H.J.; Coad, B.R. Surface-grafted antimicrobial drugs: Possible misinterpretation of mechanism of action. Biointerphases 2018, 13, $06 \mathrm{E} 409$.

46. Tachi, T.; Epand, R.F.; Epand, R.M.; Matsuzaki, K. Position-dependent hydrophobicity of the antimicrobial magainin peptide affects the mode of peptide- lipid interactions and selective toxicity. Biochemistry 2002, 41, 10723-10731. 
47. Mowery, B.P.; Lee, S.E.; Kissounko, D.A.; Epand, R.F.; Epand, R.M.; Weisblum, B.; Stahl, S.S.; Gellman, S.H. Mimicry of antimicrobial host-defense peptides by random copolymers. Journal of the American Chemical Society 2007, 129, 15474-15476.

48. Cavallaro, A.A.; Macgregor-Ramiasa, M.N.; Vasilev, K. Antibiofouling properties of plasmadeposited oxazoline-based thin films. ACS Applied Materials \& Interfaces 2016, 8, 63546362.

49. Kingshott, P.; Wei, J.; Bagge-Ravn, D.; Gadegaard, N.; Gram, L. Covalent attachment of poly (ethylene glycol) to surfaces, critical for reducing bacterial adhesion. Langmuir 2003, 19, 6912-6921.

50. Maddikeri, R.; Tosatti, S.; Schuler, M.; Chessari, S.; Textor, M.; Richards, R.; Harris, L. Reduced medical infection related bacterial strains adhesion on bioactive RGD modified titanium surfaces: a first step toward cell selective surfaces. Journal of Biomedical Materials Research Part A 2008, 84, 425-435.

51. Sileika, T.S.; Kim, H.-D.; Maniak, P.; Messersmith, P.B. Antibacterial performance of polydopamine-modified polymer surfaces containing passive and active components. ACS Applied Materials \& Interfaces 2011, 3, 4602-4610. 


\section{Supplementary Information for}

\section{Antimicrobial peptides grafted onto a plasma polymer interlayer platform: performance upon extended bacterial challenge}

Stefani S. Griesser, Marek Jasieniak, Krasimir Vasilev, Hans J. Griesser*

Future Industries Institute, University of South Australia, Mawson Lakes, SA 5095, Australia

* Author for correspondence; email hans.griesser@unisa.edu.au

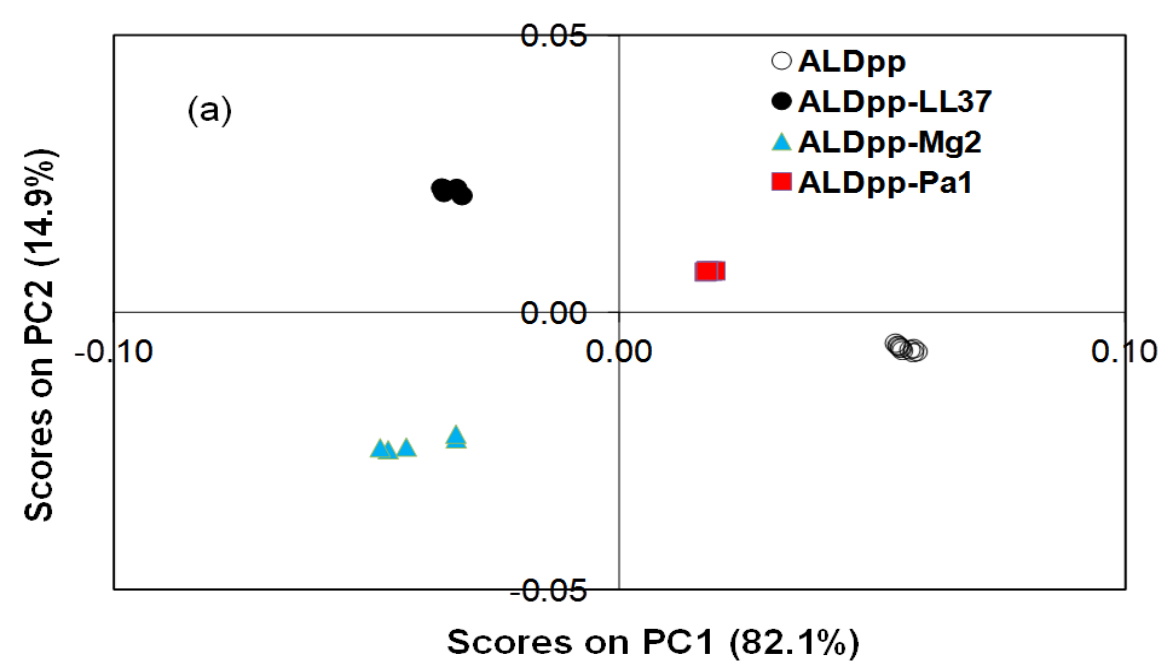

Figure S1: Scores plot on PC1 and PC2 for 3 surfaces with covalently immobilised antimicrobial peptides; 190 positive fragment ions were used in the calculations. 

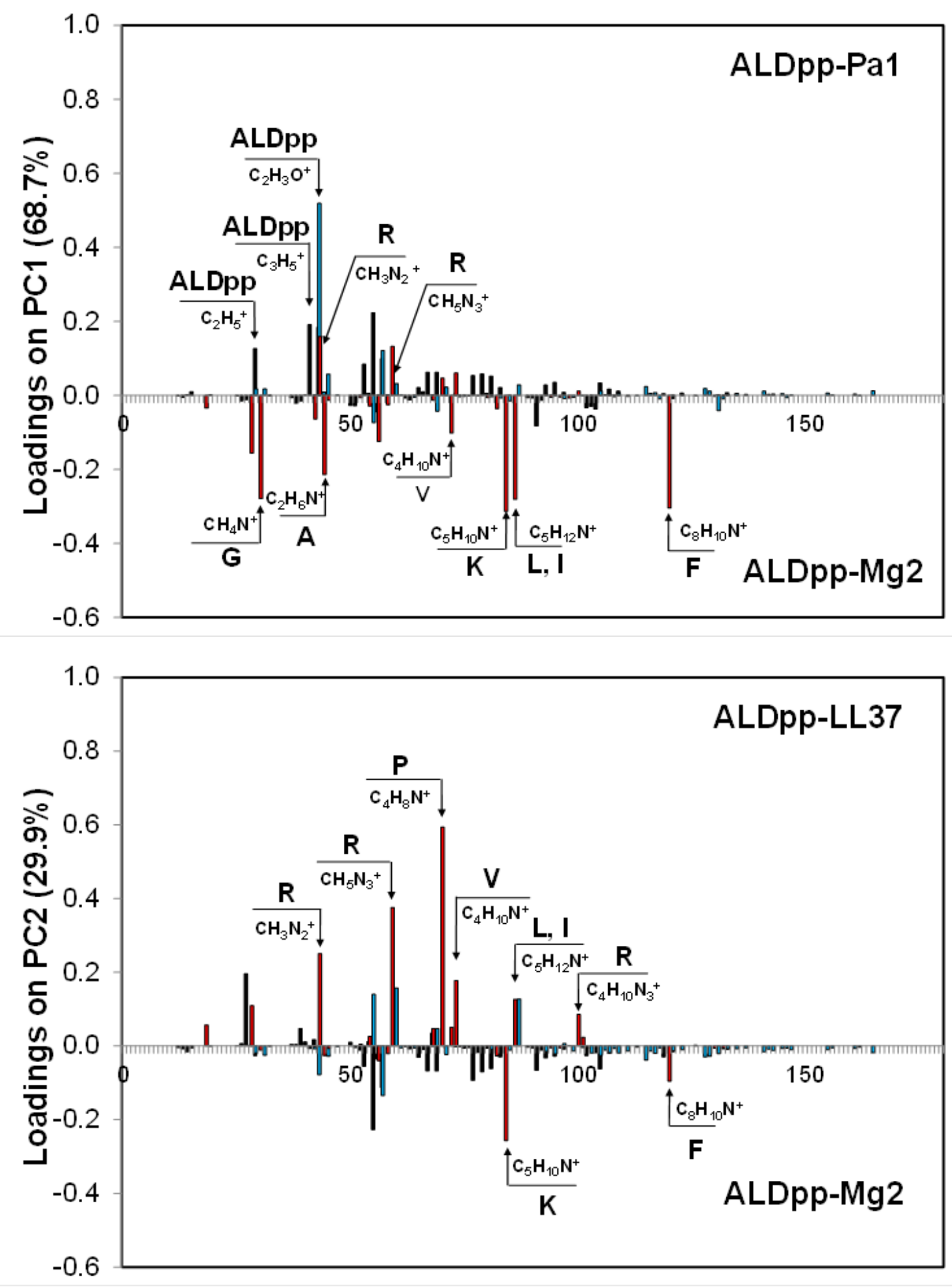

Figure S2: Loadings of positive fragments on PC1 and PC2 for surfaces with covalently immobilised antimicrobial peptides 